\title{
Effects of Acute Low-Salinity Stress on the Activities of Catalase (CAT), Superoxide Dismutase (SOD) and Glutathiones-Transferase (GST) in Scapharca broughtonii
}

\author{
Biao $\mathrm{Wu}^{1,2}$, Aiguo Yang ${ }^{1,2}$, Jingkai Yan ${ }^{3}$, Zhihong Liu ${ }^{1,2}$, Xiujun Sun ${ }^{1,2}$, Liqing Zhou ${ }^{1,2} \&$ Guangming Zhang ${ }^{1}$ \\ ${ }^{1}$ Key Laboratory of Sustainable Development of Marine Fisheries, Ministry of Agriculture, Yellow Sea \\ Fisheries Research Institute, Chinese Academy of Fishery Sciences, Qingdao, PR China \\ ${ }^{2}$ Laboratory for Marine Fisheries Science and Food Production Processes, Qingdao National Laboratory for \\ Marine Science and Technology, Qingdao, PR China \\ ${ }^{3}$ Laizhou Aquatic Technology Extension Station, Yantai, PR China \\ Correspondence: Aiguo Yang, Key Laboratory of Sustainable Development of Marine Fisheries, Ministry of \\ Agriculture, Yellow Sea Fisheries Research Institute, Chinese Academy of Fishery Sciences, Qingdao 266071, \\ PR China. E-mail: yangag@ysfri.ac.cn
}

Received: October 26, 2019

Accepted: November 10, 2019 Online Published: November 25, 2019

doi:10.5539/jmbr.v9n1p172

URL: https://doi.org/10.5539/jmbr.v9n1p172

\begin{abstract}
Salinity is an important environmental factor of osmotic pressure which is closely related to growth and development of aquatic organisms. Some physiological studies regarding to challenge of salinity have been reported in marine shellfish. However, information about the effects of acute low-salinity stress on the enzyme activities in ark shell, Scapharca broughtonii, is still limited now. In this study, the enzyme activities of catalase (CAT), superoxide dismutase (SOD) and glutathiones-transferase (GST) in five tested tissues of S. broughtonii under different salinity $(10,15,20,25$ and $30 \%$ ) for different challenged time $(24,48,72$ and 96h) were investigated. The dynamic change of the three enzyme activities after challenged were further analyzed according to the detected data. Results revealed that low-salinity stress generated great change of CAT, SOD and GST activities in organism, but the change peculiarity in different tissues was different in some degree. Especially, two of the five tissues, hepatopancreas and foot, showed special characteristics responding to the low-salinity stress. It also showed that the variations of the three enzymes activities have tissue specificity and time sequentiality in S. broughtonii.
\end{abstract}

Keywords: Scapharca Broughtonii, Salinity Stress, Enzyme Activity, Dynamic Change

\section{Introduction}

The ark shell, Scapharca broughtonii, is one of the most commercially important shellfish distributed in China, Korea and Japan, and has become a popularly cultured species in North China due to its high economic value in recent years (Xia et al., 2015; Zheng et al., 2015). However, the wild yield and resource of S. broughtonii have been suffering to severe population decline because of over-exploitation, disease outbreak, and the deterioration of environmental conditions over the past few decades ( $\mathrm{Li}$ et al., 2013; Tian et al., 2012). Therefore, it is very difficult to meet market demand because of insufficient wild yield, which promoted the development of cultured S. broughtonii in China (Bai et al., 2016; Hong et al., 2002). To extend culture field and develop culture mode are effective ways to resolve this contradiction. In North China, many coastal areas containing rich-nutrient and variety-algae are very suitable for the growth of shellfish, especially in some coastal estuary areas with injection of freshwater (Feng et al., 2015). But in such areas, the salinity condition varies frequently, so the organisms that live here should constantly adjust physiological functions to adapt to great salinity change (Lee et al., 2012). This study will be a great significance for improving salinity adaptability and expanding culture fields of $S$. broughtonii, and provide new insight into osmoregulatory mechanisms of shellfish for accompany acclimation to salinity change.

Salinity is an important environmental factor of osmotic pressure which is closely related to aquatic organisms for survival and evolve. The physiological reactions and tolerance against changes of salinity have been reported in several aquatic animals (Blewett et al., 2015; Berg et al., 2015; Hu et al., 2015; Nikapitiya et al., 2015). Salinity 
changes often cause stress reaction of marine organisms, and make the body produce excess reactive oxygen species which do harm to the body. However, most marine organisms have evolved perfect antioxidant defense system which can remove free radicals, reducing damage from oxygen stress. The effect of salinity on the enzyme activity of marine organisms have already been reported in some previous studies. Regarding to studies on response to salinity stress, many reported focused on Catalase (CAT), Superoxide dismutase (SOD) and Glutathiones-transferase (GST), and so on. The main objectives of this study were to investigate the response of enzymes activities to low-salinity challenge, enriching data regarding the research on salinity stress in S. broughtonii.

\section{Materials and Methods}

\subsection{Animals and Low-Salinity Challenge Experiment}

The healthy ark shell, S. broughtonii with averaging shell length of about $35 \mathrm{~mm}$, were collected from an aquaculture zone in Huangdao (Qingdao, China) and then acclimated at $20^{\circ} \mathrm{C}$ for one week in the plastic container with $10 \mathrm{~L}$ aerated seawater before experiment processing. The cultured seawater was renewed twice a day and the $S$. broughtonii were fed with algae every four hours. The $S$. broughtonii were divided into five groups with 30 individuals in each, and then acclimated to low-salinity challenge with salinity gradient of 10, 15, 20 and 25 while the control group was acclimated in 30. Five tissues (hepatopancreas, mantle, gill, foot and adductor muscle) of ark shell from each group were randomly sampled at 24, 48, 72 and 96h, respectively (Yin et al., 2010; Schmitz et al., 2016). Each sample was collected triply on ice. Tissues were washed with pre-cooled saline $(0.9 \%)$ firstly, and then put into liquid nitrogen quickly, stored at $-80^{\circ} \mathrm{C}$ until used.

\subsection{Enzymatic Determination}

The tissues were cut into small pieces, and then homogenized in $0.9 \%$ physiological saline and centrifuged at $3000 \mathrm{rpm}$ for $10 \mathrm{~min}$ at $4^{\circ} \mathrm{C}$. After centrifuged, the pellet was removed, and supernatant selected. Those were sampled to detect the enzyme activities of CAT, SOD and GST by using the kit from Nanjing Jiancheng Bioengineering Corp (Nanjing, China).

\subsection{Statistical Analysis}

The values showed in this study were obtained via three parallel experiments. The mean values \pm SD were showed in the figures. The significant difference between control and treatment group was performed using one-way analysis of variance (ANOVA), and the significance level value was set at $p=0.05$.

\section{Results}

\subsection{Enzyme Activity Change of CAT}

Effect of low-salinity challenge on CAT activity was shown in Figure 1, which indicated that the enzyme activity of CAT had different change tendency in the five tissues of hepatopancreas, mantle, gill, foot and adductor muscle. In absolute terms, for the numerical value of enzyme activities of CAT in the control groups, they were higher in hepatopancreas and mantles than that in other three tissues, while the lowest one was in feet. And generally, the activities of CAT enzyme in the five tissue were enhanced by low-salinity stress other than some individual values. The CAT activities in mantle, gill, and muscle showed some similar regularities and the change were relatively slight comparing to the value of control group, and most enzyme activities showed rising tendency along with the challenge time going on. However, compared to the control group, the CAT activities in hepatopancreas and feet showed stronger response to the stress, which the degree of change is closely related to stress intensity, especially the salinity-challenged groups 10 and 15 . For the hepatopancreas, CAT activities under the condition of salinity-challenged of 10 and 15 increased by $140 \%$ and $100 \%$ at $24 \mathrm{~h}$ after challenged $(p<0.05)$, while by $170 \%$ and $200 \%$ in foot $(p<0.05)$, respectively. There were also different performances between the two tissue, which the CAT activities in the feet increased with the extension of stress time, but decreased in the hepatopancreas.

\subsection{Enzyme Activity Change of SOD}

Dynamic change of SOD enzyme activities after low-salinity challenge was shown in Figure 2. From this picture, it showed that the low-salinity challenge also affected the SOD activities with different degree in the five tissues. As that of CAT, the SOD activities in the control groups of each tissue were relatively stable. Compared to other tissues, the challenge in the hepatopancreas showed obvious tendency of inhibiting SOD activity except for individual points. Regarding to the SOD activity in mantle, gill, foot and adductor muscle, most of them went up during the early treated time, and decreased accompanied by treated time going on, and went back to initial level in mantle and adductor muscle at $48 \mathrm{~h}$, as gills and feet at $72 \mathrm{~h}$. Relatively, the low-salinity stress had a greater effect on SOD activity of feet. 


\subsection{Enzyme Activity Change of GST}

Figure 3 indicated the change status of GST activities after low-salinity challenge. In the normal groups, the highest GST activity was in hepatopancreas while the lowest was in foot. Compared to the control, the GST activities in all tested tissues had rising trend with salinity decline, and what's more, the rising degree was proportional to the extent of salinity. Two main characteristics of GST enzyme activity were shown in Figure 3 in different tissues. Regarding to the response to treated time, GST activity in hepatopancreas decreased firstly and then went up, while the highest value was twice than the lowest one. However, GST activities in mantle, gill, foot and adductor muscle showed declined trend, with gill and adductor muscle GST activities adjusting to the normal levels at $48 \mathrm{~h}(p<0.05)$, mantle and foot at $72 \mathrm{~h}(p<0.05)$. And also, the GST activity under low-salinity treatment in foot kept high level at $24 \mathrm{~h}$ and $48 \mathrm{~h}$, and sharply declined to normal level at $72 \mathrm{~h}$, however, that in gill, adductor muscle declined to normal level at $48 \mathrm{~h}$.

CAT activity of hepatopancreas

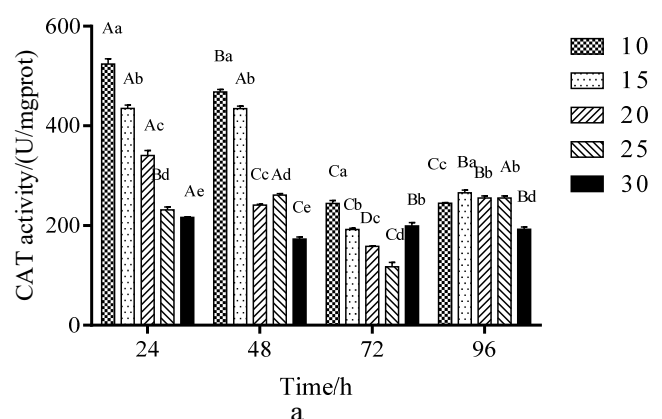

a

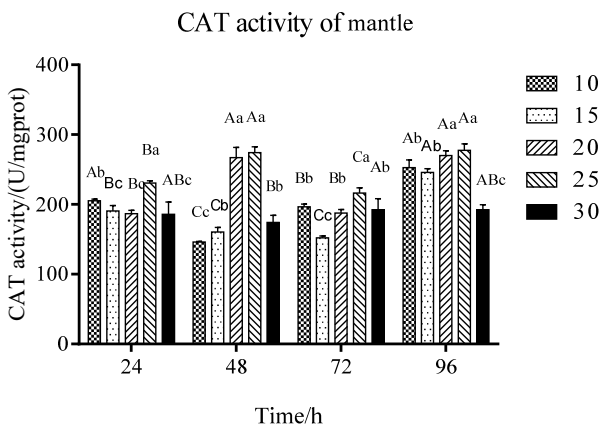

b

CAT activity of gill
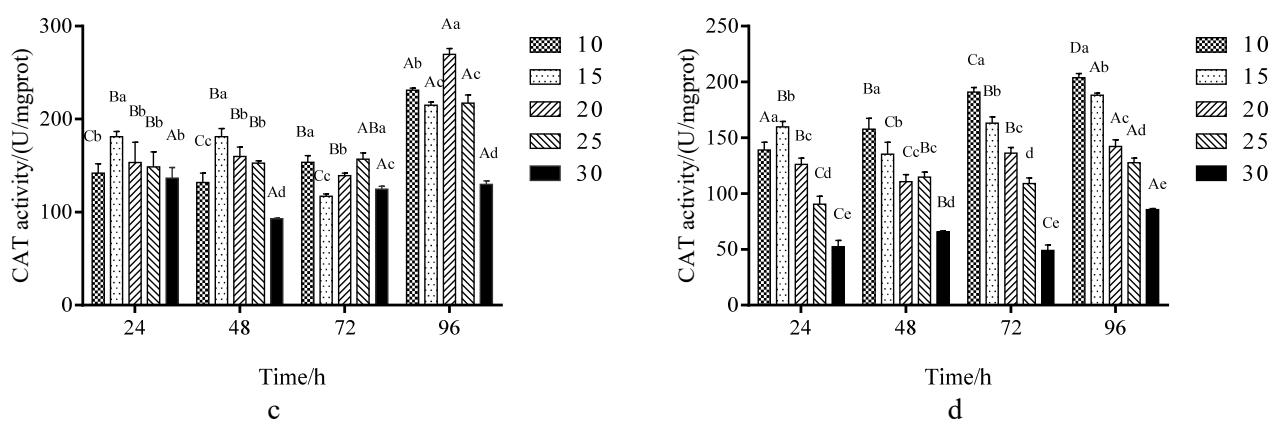

CAT activity of adductor muscle

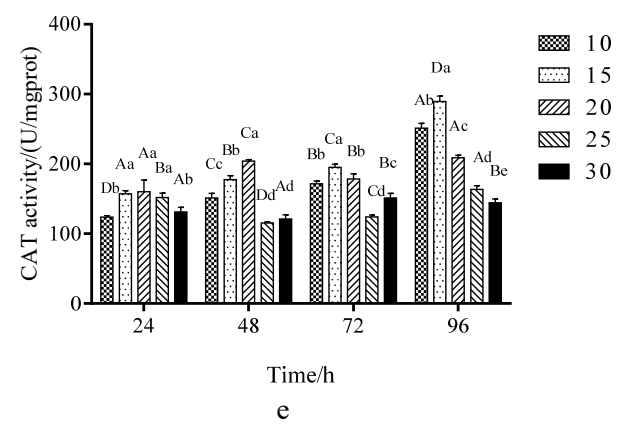

Figure 1. Effect of low salinity challenge on CAT activities in five tissues of $S$. broughtonii. Different capital indicated significant difference of enzyme activities among different times with the same salinity $(p<0.05)$; Small letters indicated significant difference of enzyme activities among different salinity at the same time $(p<0.05)$ 


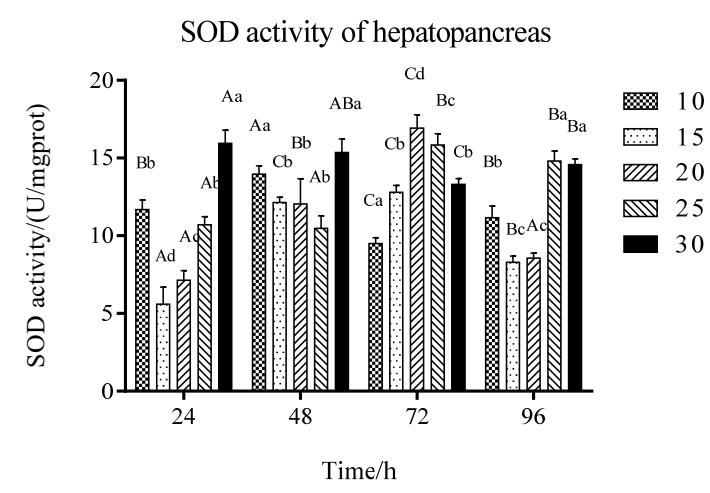

a

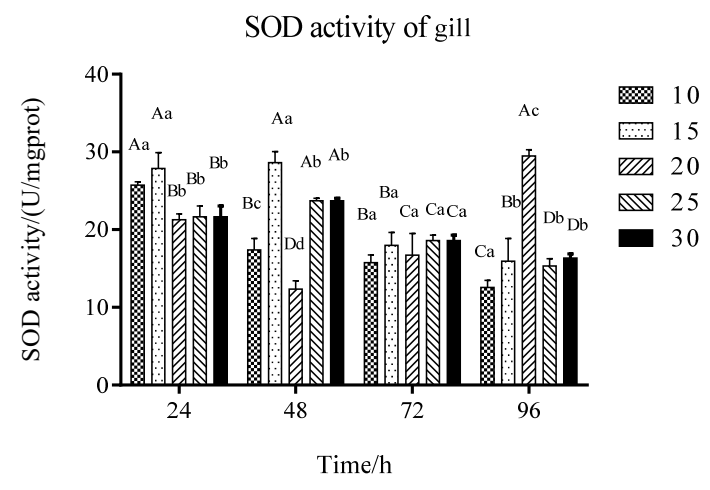

c

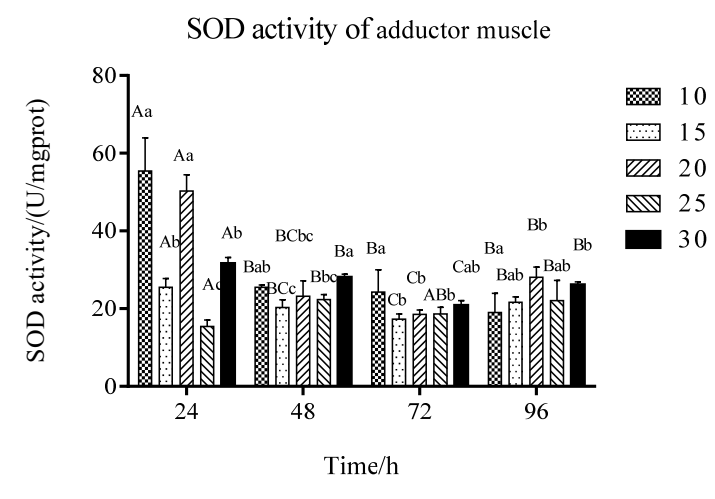

$\mathrm{e}$

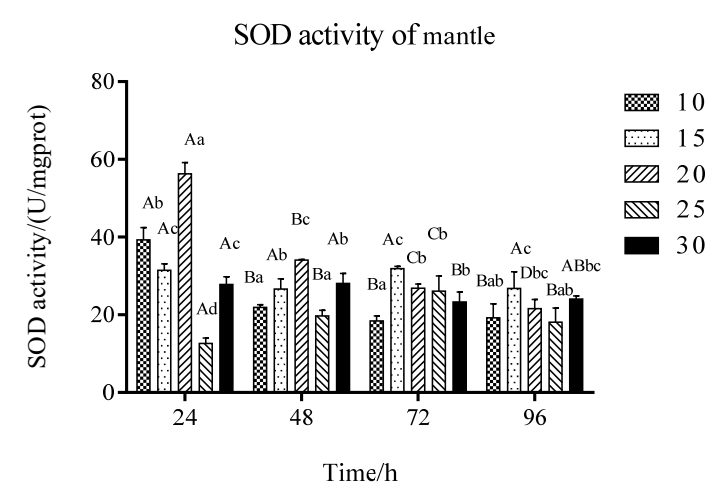

b

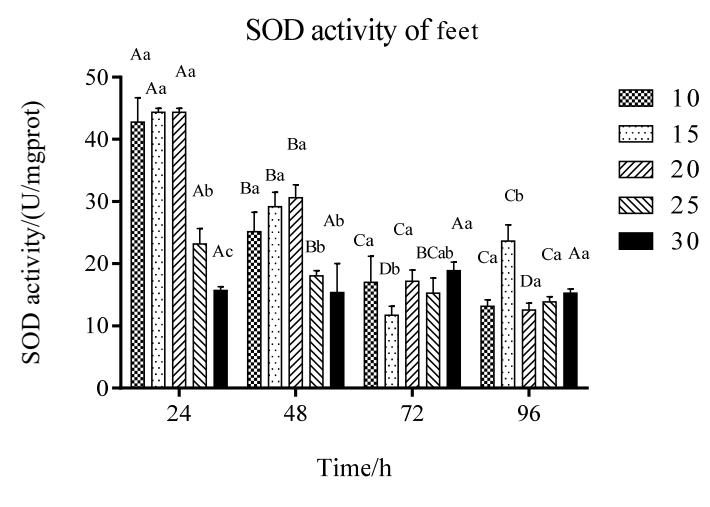

d

Figure 2. Effect of low-salinity challenge on SOD activities in five tissues of S. broughtonii. Different letters' meanings were as same as Figure 1 shown 
GST activity of hepatopancreas

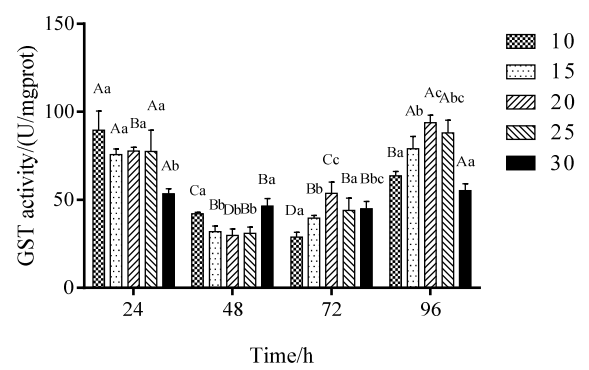

a

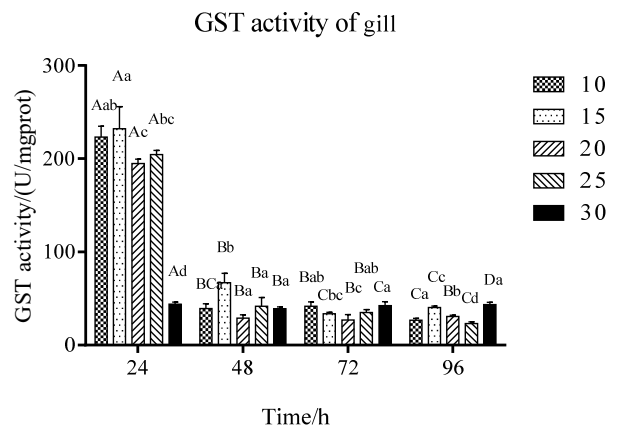

c

GST activity of adductor muscle

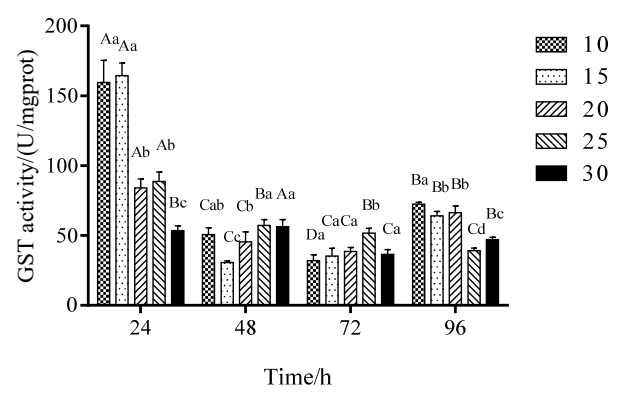

GST activity of mantle

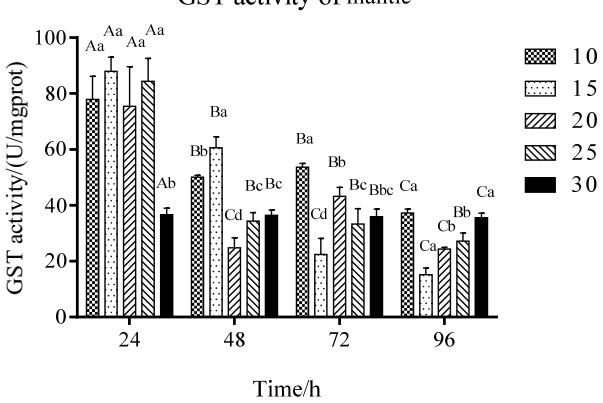

b

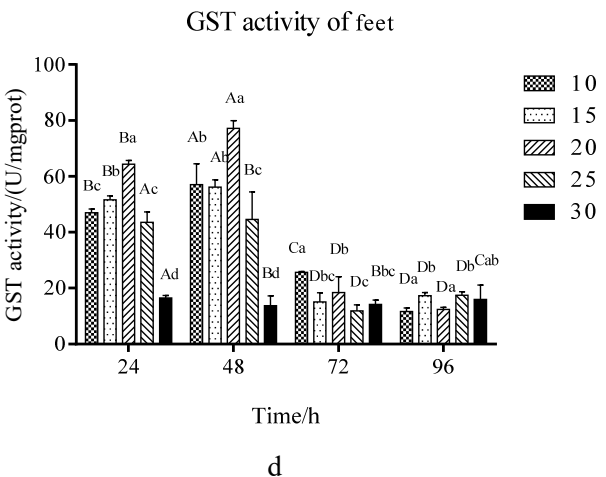

e

Figure 3. Effect of low-salinity challenge on GST activities in five tissues of S. broughtonii. Different letters' meanings were as same as Figure 1 shown

\section{Discussion}

Salinity is one of the most important environmental factors that affect the growth, survival, energy metabolism and osmotic regulation of aquatic organisms (Wang, 2005). The effect of salinity stress on physiological status has been studied in some aquatic organisms. Previous studies indicated that low-salinity stress could not only significantly affect the liver antioxidant function of juvenile Nibea albiflora (Yin et al., 2010), but also affect the growth rate, survival rate, feed intake, and feed conversion of E. carinicauda; however, the low-salinity stress could also reversely stimulate Pangasianodon hypophthalmus to grow well (Schmitz et al., 2016). Zhao et al. (2015) investigated digital gene expression (DEG) in Litopenaeus vannamei and found many genes could respond quickly at the transcriptional level to the changes caused by salinity stress, with 145 genes up-regulation and 79 genes down-regulation. In this study, we investigated the change status of three enzyme activities after low-salinity challenge in S. broughtonii. Results showed that the three enzyme activities had different performance in different tissues in response to low-salinity stress. Except for the mantle, the CAT activities in all other four tissues had rising trend under low-salinity stress, while SOD activities had declining trend with treated-time going on in all tested tissues except for hepatopancreas. And GST activities showed an rising performance with challenge of low-salinity for $24 \mathrm{~h}$, especially at the salinity degree of 10 and 15 . All results indicated that the stress of low-salinity strongly affected normal metabolism of $S$. broughtonii, which was very 
similar to the research from Wang et al. (2014) reporting about the enzymes activities of Scophthalmus maximus. Salinity stress invariably leads to oxidative stress in the $S$. broughtonii's cell due to higher leakage of electrons towards oxygen during respiratory processes which result in enhancement of activated oxygen species. Salinity decline resulted in the accumulation of free radicals in the organisms, it might cause damage to the body if not be removed in time. The increased enzyme activities could reduce effectively this damage to tissues (Yang et al., 2003). However, the CAT activities in mantle changed slightly and the SOD activities in hepatopancreas had the trend of decreasing in this study, we deduced that there might be other reasons for this decline. In addition to the concentration of salinity, challenge time was also known as an import factor to significantly affect marine organisms. Several studies have also documented that challenge time could cause the physiological response of organisms to salinity stress (Kanani et al., 2010; Pineda et al., 2012; Matros et al., 2014). The oxygen consumption rate and ammonia excretion rate could decrease gradually with the increase of stress time in Juvenile Trachinotus ovatus (Fan et al., 2012). In this study, the SOD and GST activities showed down-trend performance with the elongation of treated time, which was similar to M. cephalus. Except that CAT activities in hepatopancreas decrease with the elongation of treated time, CAT activities in other tissues showed an upward trend. It was also found that most enzyme activities substantially returned to control value after $72 \mathrm{~h}$. Therefore, it revealed that low-salinity stress stimulated the body to make stress response, but the time requiring for different enzymes were the different in a large extent. Enzyme activities were significantly influenced by salinity stress, the lower the salinity, the more time need for returning to normal level. This conclusion was consistent with many previous studies (Tang et al., 2012; Yang et al., 2008). There might be correlated ralationship between fast response of enzyme and instantaneous excess ROS generation. Under normal physiological conditions, production and elimination of free radicals were in equilibrium. Under low-salinity situation, the antioxidant enzyme system was stimulated with overproduction of ROS, to change the enzyme activity. The reason for the different change trend of the three enzymes might be their different functions in the process of elimination ROS. And the variations of enzyme activities in response to low-salinity showed tissue specificity and time sequentiality in $S$. broughtonii. This report on the enzyme activity analysis in respond to low salinity stress in $S$. broughtonii open a new insight into osmoregulatory mechanisms in shellfish.

\section{Acknowledgments}

This work was financially supported by National Natural Science Foundation of China (31602142), Key R\&D Program of Shandong Province (2018GHY115030), Central Public-interest Scientific Institution Basal Research Fund, YSFRI, CAFS (20603022017002) and Aquaculture Technology Innovation Cooperation with Tropical Countries along the Belt and Road.

\section{Conflict of interests}

The authors declare that there is no conflict of interests regarding the publication of this paper.

\section{References}

Bai, C., Gao, W., Wang, C., Yu, T., Zhang, T., Qiu, Z., ... Huang, J. (2016). Identification and characterization of ostreid herpesvirus 1 associated with massive mortalities of Scapharca broughtonii broodstocks in China. Diseases of Aquatic Organisms, 118(1), 65-75.

Berg, P. R., Jentoft, S., Star, B., Ring, K. H., Knutsen, H., Lien, S., ... Andre, C. (2015). Adaptation to low salinity promotes genomic divergence in Atlantic cod (Gadus morhua L.). Genome Biology and Evolution, $7(6), 1644-1663$.

Blewett, T. A., \& Wood, C. M. (2015). Low salinity enhances ni-mediated oxidative stress and sub-lethal toxicity to the green shore crab (Carcinus maenas). Ecotoxicology \& Environmental Safety, 122, 159-170.

Fan, C. Y., Ou, Y. J., Li, J. E., Yu, N., Su, H., \& Wang, G. (2012). Effects of acute salinity stress on $\mathrm{Na}+-\mathrm{K}+-\mathrm{ATP}$ and osmotic pressure of juvenile Trachinotus ovatus. Journal of Oceanography in Taiwan Strait, 31(2), 218-224.

Feng et al. (2015). Cloning and expression analysis of the GST gene in Portunus trituberculatus. Journal of Fishery Sciences of China, 22(2), 224-232.

Hong, H. K., Takahashi, S., Min, B. Y., \& Tanabe, S. (2002). Butyltin residues in blue mussels (Mytilus edulis) and arkshells (Scapharca broughtonii) collected from Korean coastal waters. Environmental Pollution, $117(3), 475-486$.

Hu, D., Pan, L., Zhao, Q., \& Ren, Q. (2015). Transcriptomic response to low salinity stress in gills of the Pacific white shrimp, Litopenaeus vannamei. Marine Genomics, 24, 297-304. 
Kanani, H., Dutta, B., \& Klapa, M. I. (2010). Individual vs. combinatorial effect of elevated $\mathrm{CO}_{2}$ conditions and salinity stress on Arabidopsis thaliana, liquid cultures: Comparing the early molecular response using time-series transcriptomic and metabolomic analyses. Bmc Systems Biology, 4(1), 177.

Lee, J., Whon, T. W., Shin, N. R., Roh, S. W., Kim, J., Park, S. K., ... Kim, Y. O. (2012). Ruegeria conchae sp. nov., isolated from the ark clam Scapharca broughtonii. International Journal of Systematic and Evolutionary Microbiology, 62(12), 2851-2857.

Li, R., Li, Q., \& Wang, C. (2013). Sibship reconstruction and effective population size estimation in mass spawning ark shell, Scapharca broughtonii, based on microsatellite analysis. Genes \& Genomics, 35(6), 703-708.

Witzel, K., Matros, A., Strickert, M., Kaspar, S., Peukert, M., Mühling, K. H., ... Mock, H. P. (2014). Salinity stress in roots of contrasting barley genotypes reveals time-distinct and genotype-specific patterns for defined proteins. Molecular Plant, 7(2), 336-355.

Nikapitiya, C., Kim, W. S., Park, K., Kim, J., Lee, M. O., \& Kwak, I. S. (2015). Chitinase gene responses and tissue sensitivity in an intertidal mud crab (Macrophthalmus japonicus) following low or high salinity stress. Cell Stress \& Chaperones, 20(3), 517-526.

Pineda, M. C., Turon, X., \& López-Legentil, S. (2012). Stress levels over time in the introduced ascidian Styela plicata: The effects of temperature and salinity variations on hsp70 gene expression. Cell Stress and Chaperones, 17(4), 435-444.

Schmitz et al. (2016). Synergic stress in striped catfish (Pangasianodon hypophthalmus) exposed to chronic salinity and bacterial infection: Effects on kidney protein expression profile. Journal of Proteomics, 142, 91-101.

Tang, X., Huang, G., Li, T., \& Zhang, X. (2012). Effects of low salinity stress on growth of juvenile Paralichthys olivaceus. South China Fisheries Science, 8, 10-16.

Tian, J. T., Liu, Z. H., Zhou, L. Q., Wu, B., Liu, P., \& Yang, A. G. (2012). Isolation and characterization of 48 polymorphic microsatellite markers for the blood clam Scapharca broughtonii (Arcidae). Gentics and Molecular Research, 11(4),4501-4507.

WANG, X. A., GUO, L., MA, A., Huang, Z. H., He, W. G., \& Ma, D. Y. (2014). Effects of tem-perature, salinity and their interaction on the activities of antioxidant enzymes of juvenile turbot Scophthalmus maxi-mus based on response surface methodology. Marine Sciences, 38(6), 17-23.

Wang, X. J. (2005). Effects of salinity on the non-specific immuno-enzymetic activity of Sebastes schlegeli. Marine Fisheries Research, 26(6), 17-21.

Xia, J., Bai, C., Wang, C., Song, X., \& Huang, J. (2015). Complete genome sequence of Ostreid herpesvirus-1 associated with mortalities of Scapharca broughtonii broodstocks. Virology Journal, 12 (1), 110.

Yang, W. J., Rich, P. J., Axtell, J. D., Wood, K. V., Bonham, C. C., Ejeta, G., ... Rhodes, D. (2003). Genotypic variation for glycinebetaine in Sorghum. Crop Science, 43(1), 162-169.

Yang, H., Pan, L., Hu, F., \& Liu, H. (2008). Effects of $\mathrm{Na}+/ \mathrm{K}+$ ratio of groundwaters on the gill ion-transport enzyme activity, plasma osmolality and growth of Cynoglossus semilaevis juveniles. Journal of Ocean University of China, 7(4), 447-452.

Yin, F., Peng, S. M., Sun, P., \& Shi, Z. H. (2010). Effects of low salinity on digestive enzyme activity in intestinal tract of juvenile silver pomfret Pampus argenteus. Marine Fisheries, 31(1), 55-60.

Zhao, Q., Pan, L., Ren, Q., \& Hu, D. (2015). Digital gene expression analysis in hemocytes of the white shrimp Litopenaeus vannamei, in response to low salinity stress. Fish and Shellfish Immunology, 42(2), 400-407.

Zheng, L., Wu, B., Liu, Z., Tian, J., Yu, T., Zhou, L., ... Yang, A. (2015). A manganese superoxide dismutase (MnSOD) from ark shell, Scapharca broughtonii: Molecular characterization, expression and immune activity analysis. Fish and Shellfish Immunology, 45(2), 656-65.

\section{Copyrights}

Copyright for this article is retained by the author(s), with first publication rights granted to the journal.

This is an open-access article distributed under the terms and conditions of the Creative Commons Attribution license (http://creativecommons.org/licenses/by/4.0/). 